\title{
Research
}

\section{Homeowner Associations as a Vehicle for Promoting Native Urban Biodiversity}

\author{
Susannah B. Lerman ${ }^{1}$, Victoria Kelly Turner ${ }^{2}$ and Christofer Bang ${ }^{3}$
}

\begin{abstract}
The loss of habitat due to suburban and urban development represents one of the greatest threats to biodiversity. Conservation developments have emerged as a key player for reconciling new ex-urban residential development with ecosystem services. However, as more than half of the world population lives in urban and suburban developments, identifying conservation partners to facilitate retrofitting existing residential neighborhoods becomes paramount. Homeowner associations (HOA) manage a significant proportion of residential developments in the United States, which includes the landscape design for yards and gardens. These areas have the potential to mitigate the loss of urban biodiversity when they provide habitat for native wildlife. Therefore, the conditions and restrictions imposed upon the homeowner by the HOA could have profound effects on the local wildlife habitat. We explored the potential of HOAs to promote conservation by synthesizing research from three monitoring programs from Phoenix, Arizona. We compared native bird diversity, arthropod diversity, and plant diversity between neighborhoods with and without a HOA. Neighborhoods belonging to HOAs had significantly greater bird and plant diversity, although insect diversity did not differ. The institutional framework structuring HOAs, including sanctions for enforcement coupled with a predictable maintenance regime that introduces regular disturbance, might explain why neighborhoods with a HOA had greater bird diversity. For neighborhoods with a HOA, we analyzed landscape form and management practices. We linked these features with ecological function and suggested how to modify management practices by adopting strategies from the Sustainable Sites Initiative, an international sustainable landscaping program, to help support biodiversity in current and future residential landscapes.
\end{abstract}

Key Words: CAP LTER; conservation development; homeowner associations; residential landscapes; Sustainable Sites Initiative; urban biodiversity

\section{INTRODUCTION}

More than half the world's population live in suburban and urban areas, and this proportion is expected to exceed $80 \%$ by the year 2050 (United Nations Population Fund 2007, Grimm et al. 2008). Suburbanization profoundly transforms landscapes, converting agricultural fields and wildlands into housing developments to support this burgeoning suburban population. One consequence of suburbanization is the loss of essential wildlife habitat. This, together with altered trophic dynamics and increased competition, represents one of the leading causes of biodiversity loss (Czech et al. 2000, Shochat et al. 2010, Faeth et al. 2011). An additional consequence is the continual disconnect between urban dwellers and the natural world (Miller 2005). Conservation developments offer an innovative approach to reconcile tensions between new, ex-urban development and biodiversity by identifying and protecting the ecological integrity of a property during the predevelopment phase, and by designating a significant portion (usually $>50 \%$ ) of the property as open space (Arendt 1996, Milder 2007, Pejchar et al. 2007). Using the zonation conservation planning tool, combined with principles from landscape ecology, developers strategize to ensure habitat connectivity and that lands with high ecological integrity are protected, and to maximize ecosystem services (Moilanen et al. 2005, 2011, Hersperger 2006). We explore the potential of extending the principles of conservation developments to suburban and urban areas already developed.

Retrofitting existing neighborhoods to advance the conservation of urban biodiversity requires confronting several challenges. First, within the urban matrix, the historical perception of the conservation value of protected areas far outweighs those of residential areas (Colding et al. 2006, Ernstson et al. 2010). Globally, urban-rural gradient studies have consistently shown declining bird diversity at the urban end of the gradient (Blair 1996, Chace and Walsh 2006), providing justification for concentrating management efforts toward rural areas and wildlands.

A second challenge is that residential areas are privately owned and managed as individual parcels. Voluntary programs such as the National Wildlife Federation program to certify yards as wildlife habitat (http://www.nwf.org/backyard/) and the National Audubon Society "healthy yards" program (http:// www.audubon.org/bird/at home/Healthy Yard.html) promote private management for wildlife and biodiversity, and their guiding principles, namely to incorporate native plants and structure to yards and gardens, could greatly improve local diversity. However, these projects are often spatially disparate,

\footnotetext{
${ }^{1}$ The Graduate Program in Organismic and Evolutionary Biology, University of Massachusetts, ${ }^{2}$ School of Geographical Sciences and Urban Planning, Arizona State University, ${ }^{3}$ School of Life Sciences, Arizona State University
} 
and the programs lack institutional mechanisms operating at relevant scales for coordinated biodiversity management (Borgström et al. 2006). In a bird habitat connectivity study from Stockholm, Sweden, Andersson and Bodin (2009) suggest that, although small and fragmented patches in urban areas might be non-habitat, collectively, these patches can function as large, contiguous forest areas when connected to a network of other patches.

Third, residential landscape form and management reflect the goals and priorities of multiple stakeholders, including individual homeowners, municipal governments, public institutions, and private developers. Yards and gardens that exhibit orderliness and uniformity are maintenance intensive (Nassauer 1995, Franzese 2005). They require replacing native plant communities with exotic trees, lawns, and impervious surfaces and render some patches unsuitable for native species (Burghardt et al. 2009). A mismatch emerges between residential management goals (i.e., aesthetics) and conservation priorities (i.e., restoring and protecting ecological processes) (Borgström et al. 2006, Ernstson et al. 2010).

Homeowner associations (HOA) constitute an emergent institutional actor driving landscaping and management decisions with legally enforceable rules and regulations documented in covenants, conditions, and restrictions (CCR). The HOAs coordinate management across parcels, presenting a unique opportunity to promote urban biodiversity at ecologically appropriate scales. Exploring the institutional capacities of HOAs contributes to a growing interdisciplinary residential landscapes research agenda (Andersson et al. 2007, Cooper et al. 2007, Larson et al. 2009, Colding et al. 2006, Barthel et al. 2010, Goddard et al. 2010). Within ecology, researchers have documented animal responses to residential landscape vegetation features, concluding that small-scale garden management in neighborhoods might prove beneficial for urban native diversity (Chamberlain et al. 2004, Daniels and Kirkpatrick 2006, Lerman and Warren 2011). Typically, HOAs manage all homes and common spaces within a masterplanned community (McKenzie 1996), enhancing the potential to sustain metapopulations through coordinated efforts to create habitat networks (Rudd et al. 2002, Colding et al. 2006). Here, we explore the potential of HOA management to improve urban biodiversity. First, we describe the organizational features of HOAs. Then, we synthesize long-term monitoring field data from the Central ArizonaPhoenix Long-Term Ecological Research (CAP LTER) project in Phoenix, Arizona. We compare bird, plant, and arthropod diversity and landscaping features between neighborhoods with and without HOAs. We evaluate common features in HOA landscaping guidelines and link them to animal communities. We conclude with recommendations on how HOA neighborhoods might further improve biodiversity through retrofitting existing residential landscapes to enhance the available habitat.

\section{Homeowner Associations as Environmental Managers}

Homeowner associations are "common interest organization [s] to which all the owners of lots in a planned community... must belong" (Arizona State Senate Issue Brief 2010). All property owners must pay membership dues and are contractually obliged to adhere by the rules outlined in the CCR. In the 1960s, about 500 neighborhoods belonged to a HOA in the USA, and by 2012, this number increased to 314,200 (Community Associations Institute 2012). Currently, more than 62 million Americans-predominately in the inexpensive and pro-growth Sun-Belt regions of the United States (e.g., Arizona, California, Florida) — belong to planned communities, but virtually all new developments in the United States use HOAs due to local zoning codes (McKenzie 1996, 2003). The types of developments that use HOAs include single-family subdivisions, condominiums, multi-family homes, and gated and non-gated communities, and span socioeconomic classes (Ben-Joseph 2004). The HOA developments range in size from small clusters of two or more houses to large, city-scale developments.

The proliferation of HOAs is largely driven by espoused mutual benefits for developers to maintain the integrity of their developments for perpetuity, for local governments to decrease the burden in the provisioning of services and amenities, and for homeowners to protect property values. Large-scale developers enjoy certain relaxed regulations because of the privatization of these subdivisions, which often leads to innovative designs (Ben-Joseph 2004). For example, cluster developments have higher housing densities, smaller lots, and a more efficient utility layout. Therefore, more units are built and sold on a parcel of land, benefiting the developer (McKenzie 1998). Furthermore, much of the infrastructure (for example, sewers, trash collection, streets) is provided by the HOA, thus relieving funds from local governance (McKenzie 1998). LaCour-Little and Malpezzi (2001) tracked housing values in St. Louis, Missouri between 1979 and 1999 and found that, all else being equal, homes with a HOA commanded significantly higher property values, as much as $17 \%$ more.

Homeowner associations are similar to municipal governments in organizational structure and functioning (McKenzie 1996) but distinct in their status as non-profit businesses and lack of constitutional rights for members (McCabe 2005). Developers hire legal teams to draft CCRs that enumerate rules and regulations for future residents (McCabe 2005). The CCR compels the creation of a HOA composed of a management company, elected resident board members, and in some instances, the developer (McKenzie 
1996). The HOA is responsible for property management and rules enforcement by collecting dues and fines. Homeowners or landscaping companies may be responsible for yard maintenance, which must comply with CCRs and landscaping guidelines. As landscaping guidelines are legally enforceable by virtue of CCRs, HOAs may levy fines and even foreclose on non-compliers (McKenzie 1996). Currently, the only mechanism for regulating the HOA is through litigation and, with the exception of a few notable examples (e.g., the U.S. Supreme Court decided that HOAs cannot restrict homeowners from installing solar panels; Pike 2009), court decisions usually side with the HOA.

The rules and regulations found in CCRs emerge from a combination of government regulation, developer design, and other legal considerations. Federal and state regulations are relatively immutable compared with municipal zoning that developers often receive permission to adjust through overrides. For the most part, the developer is the dominant actor determining both structure and management of residential developments, working within the limits of their budget and, in some instances, avoiding litigation (Slone et al. 2008). With the exception of environmental movements within the planning community, such as conservation subdivisions, the extent to which developers address ecological concerns beyond those mandated by the public sector is unclear. However, as many CCRs contain clauses requiring, permitting, or prohibiting specific plants, ground covers, and maintenance activities (e.g., weed removal, pest control), the CCR exerts influence on the aesthetics of the local landscape (Cook et al. 2011), and the number of landscaping guidelines contained in CCRs appears to be increasing (Larson et al. 2008), potentially influencing biodiversity.

\section{METHODS}

\section{Study Site}

Our study investigated the relationship between HOAs and biodiversity in Phoenix, Arizona, through the CAP LTER project. We focused on 39 of the 204 long-term monitoring plots, all located in residential land uses. Phoenix has experienced dramatic land-use and land-cover change over the past 20 years as it has become one of the fastest growing American cities (U.S. Census Bureau 2000). During the housing boom of the 1990s and early 2000s, desert and agricultural fields were converted to residential developments at an approximate rate of 0.4 ha per hour (Grimm and Redman 2004). Virtually all new development during this period used HOA management (Martin et al. 2003). Such patterns of rapid growth dominated by HOA management are not unique to Phoenix; subdivisions across the United States face similar challenges of improving biodiversity potential in planned communities.

\section{Bird, Plant, and Arthropod Surveys}

We synthesized bird, plant, and arthropod data from the longterm monitoring plots at CAP LTER. The bird data were collected during the winter and spring (2006-2008) at 39 monitoring plots. Three different observers visited all sites four times with a total of 12 visits per site. The bird surveys consisted of 15-minute point counts within a 40-m radius (see Lerman and Warren 2011 for additional bird survey details). The plant surveys were conducted during 2005 at 35 of the bird monitoring sites. The surveys encompassed a 30 -m radius, and every woody and non-woody plant was identified to the species level (see Walker et al. 2009 for additional plant survey details). Vegetation-dwelling arthropods were surveyed in 2005 at 34 of the bird monitoring sites and also encompassed a 30-m radius. Arthropods were sampled from the dominant woody vegetation by shaking three branches in a sweep net and collected in jars containing 70\% ethanol. The arthropods were sorted to morphologically similar groups and identified to order or the lowest taxonomic level (Hanula et al. 2009) to calculate a more accurate diversity index. With these data sets, we then calculated Shannon diversity indices for plants and arthropods, and native diversity for the birds (other diversity indices produced similar results) for each monitoring location.

\section{Surrounding Landscape Features}

We calculated the percentage of impervious surface, bare soil, and vegetation (e.g., in parks, yards) within a 1-km radius at each bird monitoring location (see Lerman and Warren 2011 for details). These three variables were highly correlated and we chose to use impervious surface as a measurement of urbanization. The two other classifications had similar results. We classified wildlands as contiguous desert patches larger than 3.2 ha (Lerman and Warren 2011). Based on previous research, desert trees emerged as an important predictor for native bird presence (Lerman and Warren 2011), and we tested whether density of native trees differed between the two neighborhood types. Here, we calculated the number of native or drought-tolerant trees along a $100-\mathrm{m}$ transect at each bird monitoring location (Lerman and Warren 2011).

\section{Homeowner Association Classification}

To determine whether a monitoring site was located in a HOA neighborhood, we used a map provided by the Maricopa County Assessor's Office from 2008 that identified housing developments throughout the Phoenix metropolitan area with a geographic information system (ArcMap 9.2; ESRI 2006). A housing development received a HOA classification when a CCR was on record (Turner and Ibes 2011). Roughly half of all monitoring sites belonged to a HOA (birds: $n=19$, plants: $n=18$, arthropods: $n=17$; Fig. 1). For the HOA housing developments, we conducted a document analysis of CCRs and landscaping guidelines on record with the Maricopa County Recorders Office. We coded these documents for 
variables identified by Larson et al. (2008) as relevant to the socioecology of residential landscapes and added additional variables for landscaping features that we predicted would have the greatest influence on biodiversity. The final list of variables that we coded for included vegetation and pest management (application of pesticides, pruning, and weed removal), plant species composition, water management, physical structures (e.g., light posts, signs, trash cans), and nuisances (e.g., loud noises, livestock) (Fig. 2). We assigned each variable a binary code: was the condition required or not required. Then, focusing on the vegetation and pest management variables, we classified a development as either requiring all, none, or half of the activities.

Fig. 1. Map of study area, including locations of neighborhoods surveyed for bird, plant, and arthropod diversity in Phoenix, Arizona. Shaded circles indicate HOA neighborhoods.

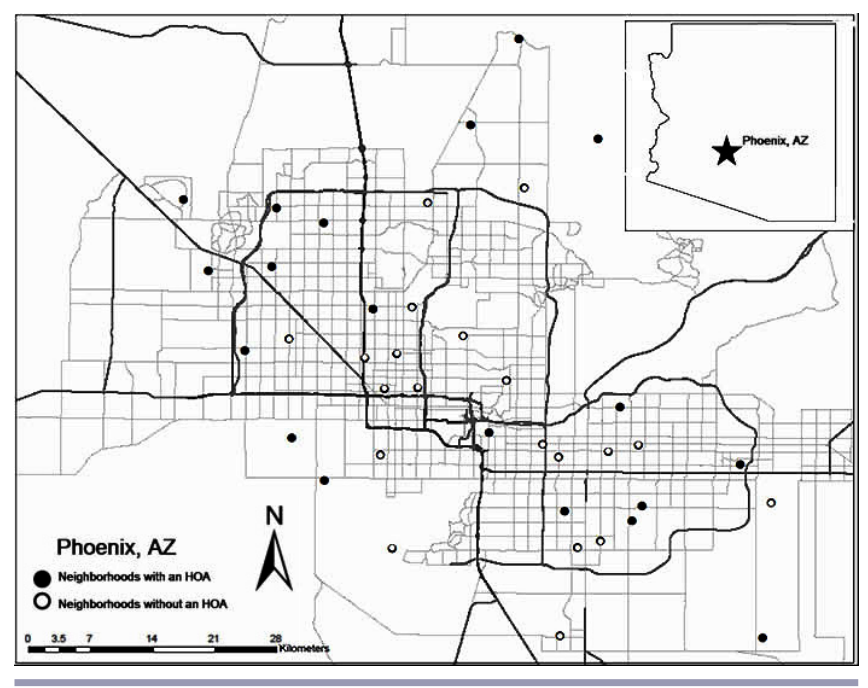

\section{Statistical Analysis}

We used $t$ tests to compare the Shannon indices for native bird diversity, the plant diversity and richness, and arthropod diversity between neighborhoods with and without a HOA. As we were primarily interested in how distinctive management regimes (i.e., HOA present or absent) related to biodiversity, we first tested whether the surrounding landscape (e.g., amount of impervious surface and distance to wildlands), socioeconomic factors (household income for the associated U.S. Census Block Group; U.S. Census Bureau 2000), and desert vegetation, differed between the two neighborhood types to account for the potential influence of these factors (Hope et al. 2003, Melles 2005, Loss et al. 2009). As housing age might influence vegetation density and maturity (Loss et al. 2009) — and in the case of Phoenix, Arizona, increased exotic vegetation conditions-and thus, making it less likely to support native birds (Lerman and Warren 2011), we conducted an analysis of covariance (ANCOVA) to test how neighborhood management (i.e., neighborhoods with or without a HOA) influenced native bird diversity while accounting for housing age.

We used the nonparametric multi-response permutation procedures (MRPP) to test whether bird species composition within HOA neighborhoods differed between these landscaping activity classifications. For this analysis, we standardized the data and reduced the number of bird species in the analysis by only including species recorded at $10 \%$ or more of the monitoring locations. Multivariate analyses benefit from deleting rare species because species with few records are often not accurately placed in ecological space (McCune and Grace 2002). The arthropod data set contained too many zeros to include in this analysis. We used the Bray Curtis distance measurement and conducted 999 permutations. We conducted our analyses with JMP 8 statistical software and R (R Development Core Team2008), using the vegan package (Oksanen et al. 2009).

\section{RESULTS}

Household income, housing age, amount of impervious surface, and distance to wildlands did not differ between neighborhood types (Table 1). Neighborhoods belonging to a HOA had significantly greater plant diversity than neighborhoods not belonging to a HOA $\left(t\right.$ test: $t=2.48_{1.32}, P$ $=0.02$, Fig. 3 ), although native tree density did not differ (Table 1). In addition, HOA neighborhoods tended to have higher plant richness ( $t$ test, $t=1.92_{1,33}, P=0.06$ ). Native bird diversity differed between the two groups of neighborhoods, and showed a trend toward increased diversity in neighborhoods with HOAs $\left(t\right.$ test: $\left.t=1.93_{1,37}, P=0.0617\right)$. When we excluded one neighborhood with extremely low native bird diversity, the relationship became significant $(t$ test: $t=2.61_{1,36}, P=0.01$; Fig. 3 ). The excluded neighborhood was recently developed from an agricultural field, suggesting that land-use legacy might have a disproportional influence on the bird composition; many of the birds in this neighborhood were more typical of agricultural fields. Regardless, the study strongly suggested a relationship between both plant and native bird diversity. We found a significant relationship between neighborhood management and bird diversity when accounting for the covariance of housing age (ANCOVA: $F$ ratio $=4.94_{1,37}, P=0.03$; Table 2). Arthropod diversity did not differ between the two neighborhood types ( $t$ test: $t=0.12_{1,31}, P=0.9$; Fig. 3 ).

Management practices differed across neighborhoods (Fig. 2). Five neighborhoods required weeding, pruning, pest removal, and disease control; six neighborhoods did not require these activities. The remaining eight neighborhoods grouped weeding and pruning, and pest removal and disease control; some neighborhoods required the former but not the latter, and 
Fig. 2. Covenants, conditions, and restrictions (CCR) for landscaping practices in HOA neighborhoods, Phoenix, Arizona.

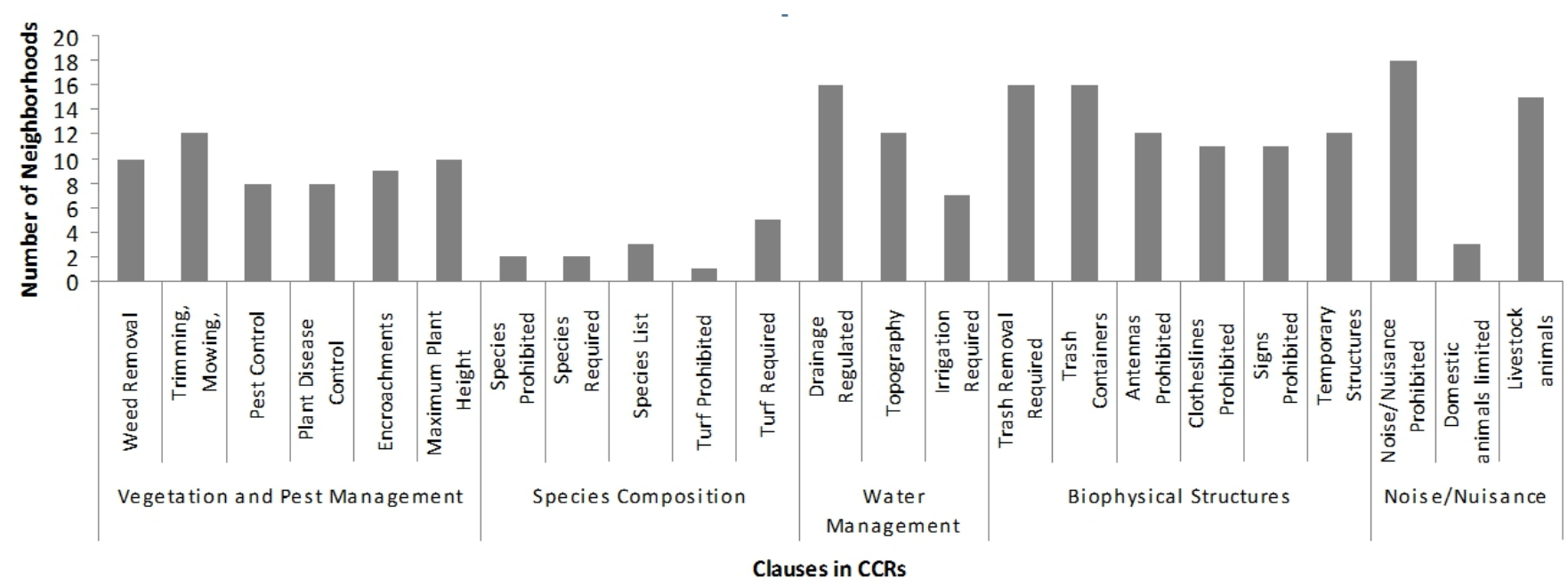

vice versa. We found no obvious patterns between bird composition and specific landscaping activities (MRPP, Chance corrected within-group agreement A: $0.02203, \delta=$ $0.4036, P=0.15)$.

Table 1. Independent variables used for comparing how landscape and socioeconomic features differed between neighborhoods with different management regimes (i.e., neighborhoods with and without a HOA). Results from $t$ test shown.

\begin{tabular}{lrrrrr}
\hline \hline Variable & $n$ & $\begin{array}{c}\text { Mean } \\
\text { HOA }\end{array}$ & $\begin{array}{c}\text { Mean } \\
\text { non- } \\
\text { HOA }\end{array}$ & $t$ ratio & $P$ \\
\hline Household income & 39 & $\$ 61,878$ & $\$ 52,645$ & 1.05 & 0.30 \\
Neighborhood age (yr) & 39 & 1984 & 1977 & 1.92 & 0.06 \\
Distance to wildlands (m) & 39 & 3246.6 & 4259.4 & -0.96 & 0.34 \\
Impervious surface (\%) & 39 & 34 & 32 & 0.40 & 0.69 \\
Desert trees & 39 & 9.39 & 6.25 & 0.86 & 0.39 \\
\hline
\end{tabular}

Table 2. Results from an analysis of covariance (ANCOVA) demonstrating how neighborhood age co-varies with neighborhood management (i.e., neighborhoods with and without a HOA) in explaining native bird diversity in Phoenix, Arizona. The insignificance of the interaction term indicates the homogeneity of the slopes was not rejected.

\begin{tabular}{lccc}
\hline \hline Variable & $n$ & $F$ ratio & $P$ \\
\hline Neighborhood management & 39 & 4.94 & 0.03 \\
Neighborhood age & 39 & 0.26 & 0.62 \\
Interaction & 39 & 0.28 & 0.60 \\
\hline
\end{tabular}

Fig. 3. Diversity relationships (bird, plant, and arthropod) between neighborhoods with a HOA and neighborhoods without a HOA in Phoenix, Arizona. Neighborhoods belonging to a HOA had greater native bird diversity and plant diversity compared with neighborhoods without a HOA. Arthropod diversity did not differ between neighborhood types. Standard error bars shown.

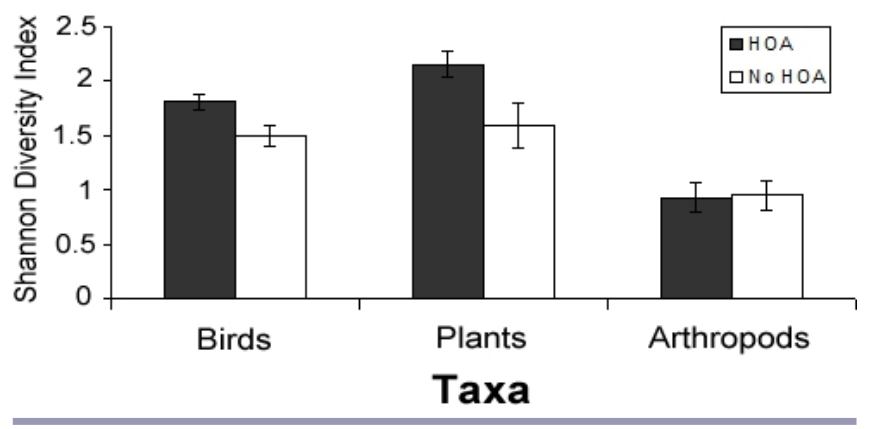

\section{DISCUSSION}

An active and enforceable landscape management plan might explain why native bird diversity was greater in neighborhoods with a HOA even though management regimes varied between neighborhoods, and these regimes did not appear to be associated with bird species composition. Variable management regimes may increase niches among the HOA neighborhoods, increasing native biodiversity. Synthesizing data from three distinct monitoring programs enabled us to garner insights across different taxa. Here, we present two 
possible, not mutually exclusive hypotheses, one from a social-ecological perspective and the other deriving from ecological theory, to suggest how management might explain why bird diversity was elevated in HOA neighborhoods.

\section{Socioecology and Management}

We propose that the institutional design of HOAs helps promote biodiversity. The CCR gives the HOA the legal authority to create and enforce rules and to sanction rule violations through monetary fines. In a meta-study of forestry practices, Pagdee et al. (2006) found a global trend that "effective enforcement" significantly influenced successful community forestry. Sanctions for enforcing good management systems, i.e., actions that promote sustainable ecosystems and human well-being, contribute to collective action (Ostrom 2009). Institutional theory suggests that both social (i.e., HOAs) and biophysical factors influence sustainable resource management in social-ecological systems (Ostrom 2009). HOA neighborhoods have welldefined boundaries, property rights, and a focus on landscaping practices and govern a resource system for yard esthetics and stabilizing property value; increased biodiversity is a byproduct of active HOA management.

Homeowners belonging to a HOA actively monitor neighborhood landscaping activities and ensure neighbors comply with the CCR. This might lead to better landscape management and possibly explains the increased diversity in the HOA neighborhood. Studies have demonstrated that forest management, (i.e., human intervention) benefits from regular monitoring and enforcement of the rules (Coleman and Steed 2009). User groups such as HOAs have the capacity to promote local stewardship, pool resources and knowledge regarding resource management, and can expand stakeholders for natural resource management (Colding et al. 2006). Lower native bird diversity in non-HOA neighborhoods might suffer from the "tyranny of small decisions" (Odum 1982:278) due to the lack of a collective management and enforcement regime. Our study did not address CCR rule enforcement, and we recommend future studies do so. Nevertheless, institutional theory provides an entry point to explain the relationship between HOA governance and environmental outcomes.

\section{Ecological Theory and Management}

Alternatively, we suggest that the differences between neighborhoods with and without HOAs may be due to differences in disturbance regimes. The intermediate disturbance hypothesis states that diversity peaks when a disturbance is neither too scarce or frequent, or too mild or intense (Connell 1978). Urbanization has been likened to a disturbance (McKinney 2006), and the intensity varies along an urban-rural gradient. In HOA neighborhoods, rapid localized landscaping disturbances (e.g., weed removal, pruning, and replacement of diseased plants), might have a strong link to the structuring of animal communities (Faeth et al. 2011). These aesthetically driven human disturbances on residential landscapes are important to the form and function of the social-ecological system but are distinct from those found in non-urban ecosystems. Furthermore, human disturbances may have positive or negative implications for biodiversity (e.g., pruning improves the esthetics but removes habitat for arthropods). In HOA neighborhoods, disturbances are predictable and have consistent landscape maintenance.

HOA residents are exposed to a wide variety of plants and may prefer to include "one of everything" in their yards (Faeth et al. 2011), elevating plant diversity in HOA neighborhoods. This in turn might support greater numbers of individual birds and bird species (Luck and Smallbone 2011). Residents of non-HOA neighborhoods might engage in similar landscaping practices as those in HOA neighborhoods, but lack consistent rules, sanctions for enforcement, and publicly available governing documents needed to empirically investigate management activities.

\section{Spatial Scales}

We failed to find a direct link between arthropod diversity and the presence of a HOA. Most likely, the sampling design of surveying one plant per neighborhood was too small scale to accurately reflect the arthropod community throughout the neighborhood. Nonetheless, the inclusion of these data provides additional insight regarding how other taxa might respond to residential developments. The results might also suggest the scheduling of landscaping activities might not be associated with arthropod diversity. Perhaps HOA neighborhoods were no better or worse for arthropod communities than those in non-HOA neighborhoods. For example, removing leaf litter, regardless of frequency, could have detrimental effects for arthropods by depleting favorable microhabitat conditions for soil microarthropods, mainly in terms of food and moisture conditions (Sousa et al. 1997). To further exacerbate conditions for insects, exterminators working in residential landscapes perform a blanket approach rather than targeting specific harmful insects for removal. This action might influence arthropod diversity, whereby some predatory insects might be more susceptible to pesticide application (Papachristos and Milonas 2008). An additional consequence of decimating the insect population is the elimination of a potential food source for insectivorous birds, a guild often missing or greatly reduced in urban environments (Chace and Walsh 2006, Bang et al. 2012). Therefore, it is expected that current strategies for managing suburban yards, such as use of leaf blowers and herbicides, have detrimental effects on arthropod communities in both HOA and non-HOA neighborhoods. We recommend designing future arthropod studies to explicitly test the links between common landscaping practices and arthropod communities. Ideally, these studies should sample arthropods from a variety of substrates and vegetation. 
We recognize that birds and other wildlife reply to multiple scales (Hostetler and Holling 2000). For example, Chamberlain et al. (2004) suggest that bird occurrence in yards in the United Kingdom was strongly dependent on broader scale landscape features. Daniels and Kirkpatrick (2006) found that yard structure-particularly the occurrence of native plants - and the broader landscape influence bird distribution and composition in Australia. Lerman and Warren (2011) demonstrated with partition analysis that yard features and socioeconomic factors explained nearly twice as much of bird diversity patterns in Phoenix residential neighborhoods than did landscape features. By testing whether landscape features differed between neighborhoods with and without a HOA enabled us to account for their similarities, regardless of neighborhood management.

Vegetation in neighborhood common areas (e.g., street trees) and urban parks also influences urban bird biodiversity (e.g., Fernandez-Juricic 2000). Our study demonstrates differences in biodiversity based on management in HOA and non-HOA neighborhoods above and beyond landscape features. We failed to find significant differences between impervious surface (Table 1) and housing age between HOA and nonHOA neighborhoods, suggesting that effects of vegetation densities and home ages were similar. Although not significant at the 0.05 cut-off, newer neighborhoods were slightly more likely to have a HOA. Housing age reflects the time since the initial disturbance to the landscape (McKinney 2006) and can elucidate how time lag effects influence urban bird communities. The results from the ANCOVA gave additional support for our argument that management differences and institutional factors were primarily responsible for the increased native bird diversity in HOA neighborhoods.

Although the collective actions for landscaping activities that were prevalent within a HOA had the potential to improve wildlife conditions, some of these activities might have detrimental impacts and disturb bird habitat. In a survey of 43 HOAs from Phoenix, Arizona, Fokidis (2011) found that all restricted thorny vegetation (trees and shrubs) and imposed size limitations for cacti. These restrictions might be disadvantageous for native birds with specific habitat requirements and might hinder native species distribution across suburban areas (Blair 1996, Fokidis 2011).

\section{MANAGEMENT IMPLICATIONS: RETROFITTING HOMEOWNER ASSOCIATIONS}

Homeowner associations have an institutional framework in place to assist with enforcement of landscaping activities at a scale larger than individual parcels but smaller than a municipality, a spatial scale better matched for bird conservation efforts (Warren et al. 2008) and other urban wildlife. In addition, the trend toward greater bird diversity in HOA neighborhoods suggests a potential partner for conservation biologists and land managers to further maximize habitat conditions for native wildlife and improve the conservation value of urban ecosystems. In this section, we present general guidelines to help retrofit HOA neighborhoods by integrating ecological landscaping features at a neighborhood scale from the Sustainable Sites Initiative (SSI; 2009). HOAs provide regularity in landscape management (i.e., disturbance), and incorporating the SSI may add some intentionality to the disturbance regime. In addition, HOAs may capitalize on the institutional features identified in Ostrom's (2009) natural resource management framework by incorporating SSI features.

The SSI is a national certification system that guides the creation and implementation of sustainable landscapes. Modeled after the Leadership in Energy Efficiency and Design for Neighborhood Development (LEED-ND) certification system, the SSI awards points for specific sustainable landscape features from the design, construction, and postconstruction phases of development that help promote ecosystem services. Many of these features can be implemented in the post-construction phase of a development, and roughly half of all available points are applicable for current neighborhoods belonging to a HOA as many of the landscaping and management features of the CCR are duplicated in the SSI (Fig. 4). These include maintenance activities, plant species, and hydrology. Incorporating SSI into the existing HOA management constitutes an incremental and pragmatic mechanism for retrofitting subdivisions.

The potential institutional fit between SSI and HOAs lies in the compatibility between rating systems and master planning, for which the LEED-ND has already established a precedent. The LEED-ND rating system has guided new and retrofit developments in the USA, Canada, China, and Mexico, many of which use CCRs (Farr 2008, U.S. Green Building Council 2011). The SSI is the ecology-centric derivative of the LEEDND rating system that emphasizes ecosystem service delivery as opposed to resource efficiency through building design and neighborhood configuration.

The institutional design of the HOA similarly complements the SSI rating system during the construction and postconstruction phases of development. During the construction phase, the CCR guidelines ensure that homebuilders and landscape architects comply with environmental goals. During the post-construction phase, the CCR serves as an instructional guide for homeowners and management companies in the maintenance of residential properties and common areas that could potentially be derived from the SSI rating system. Additionally, the CCR provides the HOA with the legal authority to oversee community affairs and to levy fines and even evict delinquent homeowners. The HOA could oversee environmental monitoring required by SSI and exercise its authority to ensure homeowners adhere to environmental goals. If the requirements are not met, or the upkeep lags, then 
Fig. 4. Common features shared between the covenants, conditions, and restrictions (CCR) and the Sustainable Sites Initiative (SSI). For each section, we identify points available for retrofitting landscapes, goals of each section, examples of landscaping activities, and benefits for people and biodiversity of adapting the SSI features. Shaded circles and rectangles denote SSI features and white circles and rectangles denote CCR features.

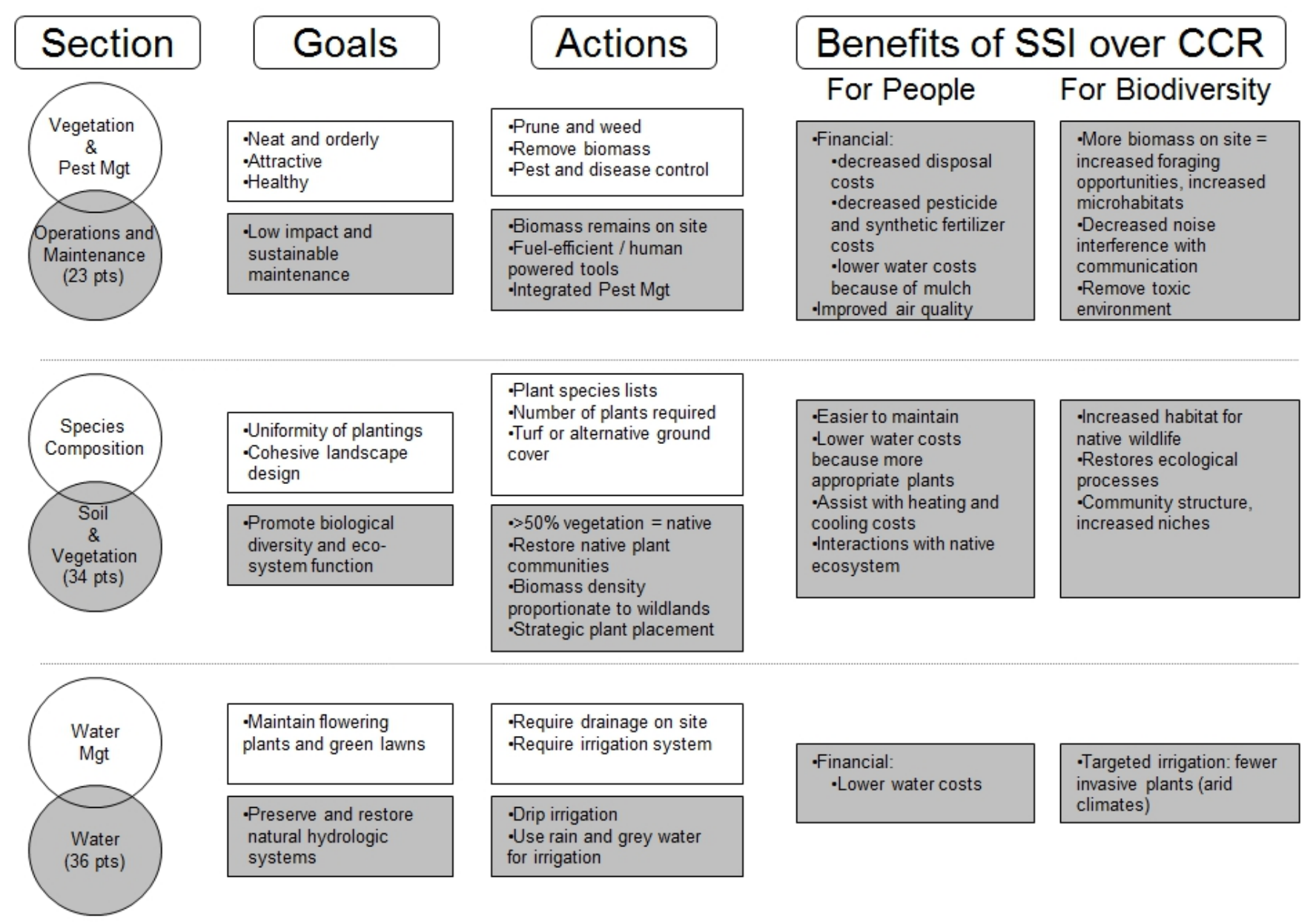

SSI status will be revoked. This ability to enforce sanctions might enable the SSI to promote greater levels of biodiversity in HOA neighborhoods (Ostrom and Nagendra 2006).

Similar to the CCR, the SSI suggests methods for managing the yard, and these actions are awarded with points toward sustainability status. For example, the current method of pruning shrubs and bushes in Phoenix HOA neighborhoods radically alters the natural structure of the plant (Fig. 5a, b). To adhere with SSI guidelines, the CCR could limit the amount of biomass trimmed per maintenance session, leave the vegetation on site, and accrue points for SSI status. These actions in turn might improve the habitat complexity and increase native diversity.

We recognize the many barriers associated with implementing such changes to existing HOA neighborhoods. Making changes to a CCR requires voting by the HOA board, a lawyer to draft a new CCR, redesigning the landscape plan, and devising a system for evaluation and monitoring. Removing barriers to change (e.g., supermajority voting) would increase flexibility and enable HOAs to take an adaptive management approach.

Disseminating information about SSI to HOAs represents another important challenge. Engaging with the Community Associations Institute (2012) and similar entities, coupled with ensuring the science behind this study is communicated effectively, will begin to address this challenge. Establishing a mechanism to license a HOA as a sustainable site will help encourage HOAs to adopt the SSI and assist with the transition to a SSI neighborhood. 


\section{CONCLUSION}

Urbanization currently contributes to the homogenization of urban diversity (McKinney 2006), but HOAs can address this through design and management to provide a variety of niches to support rich animal communities. One of the primary advantages of HOA management is the neighborhood-scale design and management. The CCR can promote multiple habitat patches and zones throughout a neighborhood and assign management regimes appropriate for different species composition (Andersson et al. 2007). Diverse landscapes provide the co-benefits of pleasing aesthetics while providing multiple niches for wildlife (Rosenzweig 2003). Linking multiple HOAs within a city and with various urban land uses will assist with their function at a scale that extends beyond the HOA boundary (Borgström et al. 2006). This larger network of HOAs can extend the benefits of adopting the SSI framework to multiple scales.

Fig. 5. Example of the variation in landscaping activities. (a) Typical pruned shrub in residential yards in Phoenix, Arizona. (b) A similar shrub, unpruned. Allowing shrubs to grow out could have beneficial implications for arthropod diversity.
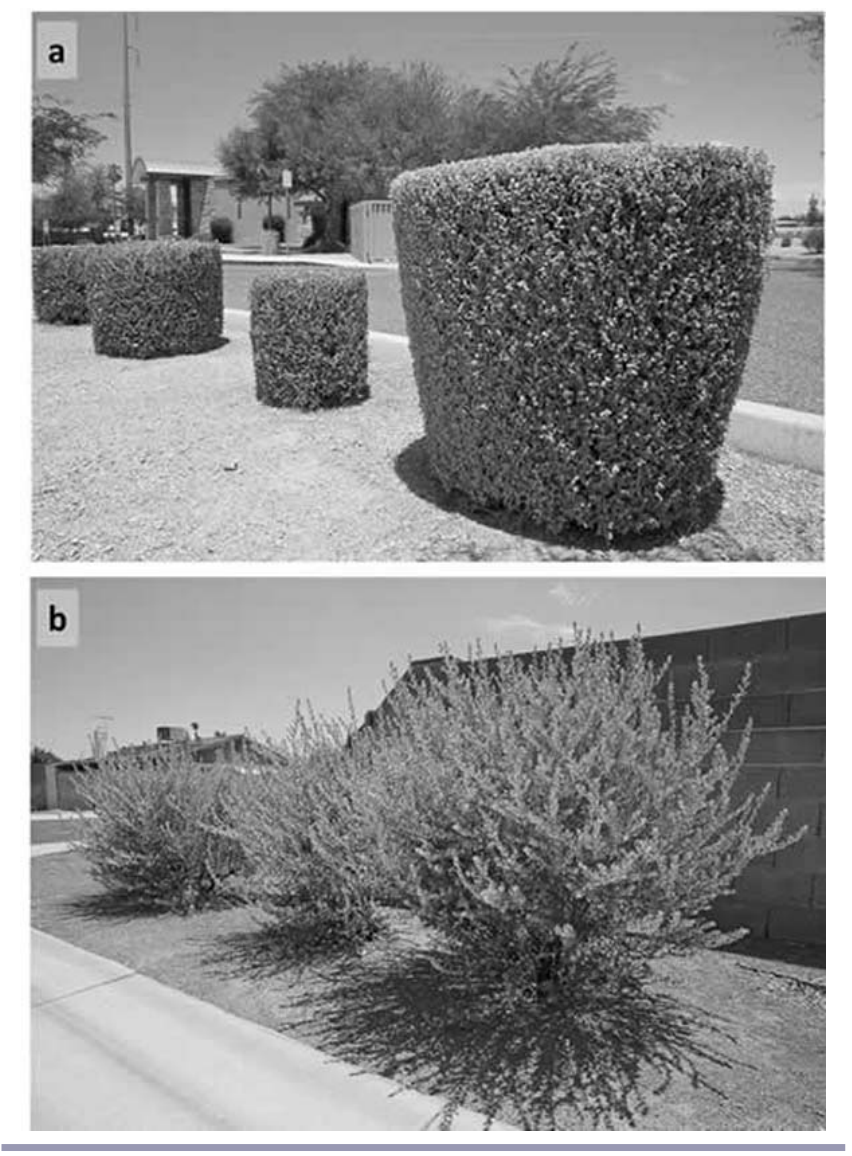

Encouraging active stewardship from homeowners through the SSI framework meets a homeowner's desire to gain local ecological knowledge and solidifies a strong place attachment and a deeper appreciation for local nature (Horwitz et al. 2001, Ryan 2005). Furthermore, when stewardship results in more biologically diverse neighborhoods, the sense of well-being elevates. Although difficult to quantify, interacting with birds and other wildlife has been shown to improve urban dwellers' connection with nature and well-being (see, for example, Yang and Kang 2005, Fuller et al. 2008, Irvine et al. 2009). These studies suggest that managing for urban biodiversity in residential yards and gardens leads to positive human-nature interactions (Fuller et al. 2007) and might promote additional stewardship activities that extend beyond a steward's neighborhood (Turner et al. 2004, Miller 2005).

As our suburbs continue to swell, identifying innovative tools and partners for managing housing developments is essential for the conservation of urban nature (Borgström et al. 2006). Adapting features from the SSI to HOAs might further improve urban diversity by incorporating landscaping activities that have direct benefits for birds and other wildlife. Homeowner associations, with their governance, regulatory structure, relatively large scope of influence, and focus on landscaping practices, present a viable venue for active conservation biologists to ensure that urban ecosystems are not devoid of native diversity.

Responses to this article can be read online at: http://www.ecologyandsociety.org/issues/responses. php/5175

\section{Acknowledgments:}

We thank P. Warren, S. DeStefano, K. McGarigal, E. Jakob, and two anonymous reviewers for helpful comments on earlier drafts of this manuscript. R. Walton assisted with the CCR coding. We appreciate the work from the CAP LTER field technicians for collecting the bird, arthropod, and plant data. S. B. L. was supported by a Switzer Environmental Fellowship and a Leadership Grant from The Robert and Patricia Switzer Foundation, and the U.S. Forest Service Northern Research Station. This material is based upon work supported by the National Science Foundation under Grant No. DEB-0423704, Central Arizona-Phoenix Long-Term Ecological Research (CAP LTER). Any opinions, findings, and conclusions or recommendations expressed in this material are those of the authors and do not necessarily reflect the views of the National Science Foundation (NSF). 


\section{LITERATURE CITED}

Andersson, E., S. Barthel, and K. Ahrné. 2007. Measuring social-ecological dynamics behind the generation of ecosystem services. Ecological Applications 17:1267-1278.

Andersson, E., and O. Bodin. 2009. Practical tool for landscape planning? An empirical investigation of network based models of habitat fragmentation. Ecography 32:123-132. http://dx. doi.org/10.1111/j.1600-0587.2008.05435.x

Arendt, R. 1996. Conservation design for subdivisions: a practical guide to creating open space networks. Island Press, Washington, D.C., USA.

Arizona State Senate Issue Brief. 2010. Homeowners' association. Arizona Senate Research Staff, Phoenix, Arizona, USA. [online] URL: http://www.azleg.state.az.us/ briefs/Senate/HOMEOWNERS\%20ASSOCIATIONS.pdf

Bang, C., S. H. Faeth, and J. L. Sabo. 2012. Control of arthropod abundance, richness and composition in a heterogeneous desert city. Ecological Monographs 82:85100. http://dx.doi.org/10.1890/11-0828.1

Barthel, S., C. Folke, and J. Colding. 2010. Social-ecological memory in urban gardens-retaining the capacity for management of ecosystem services. Global Environmental Change 20:255-265. http://dx.doi.org/10.1016/j.

gloenvcha.2010.01.001

Ben-Joseph, E. 2004. Double standards, single goal: private communities and design innovation. Journal of Urban Design 9:131-151. http://dx.doi.org/10.1080/1357480042000227799

Blair, R. B. 1996. Land use and avian species diversity along an urban gradient. Ecological Applications 6:506-519. http:// dx.doi.org/10.2307/2269387

Borgström, S., T. Elmqvist, P. Angelstam, and C. AlfsenNorodom. 2006. Scale mismatches in management of urban landscapes. Ecology and Society 11(2): 16. [online] URL: http://www.ecologyandsociety.org/vol11/iss2/art16/

Burghardt, K. T., D. W. Tallamy, and G. W. Shriver. 2009. Impact of native plants on bird and butterfly biodiversity in suburban landscapes. Conservation Biology 23:219-224. http://dx.doi.org/10.1111/j.1523-1739.2008.01076.x

Chace, J. F., and J. J. Walsh. 2006. Urban effects on native avifauna: a review. Landscape and Urban Planning 74:4669. http://dx.doi.org/10.1016/j.landurbplan.2004.08.007

Chamberlain, D. E., A. R. Cannon, and M. P. Toms. 2004. Associations of garden birds with gradients in garden habitat and local habitat. Ecography 27:589-600. http://dx.doi. org/10.1111/j.0906-7590.2004.03984.X

Colding, J., J. Lundberg, and C. Folke. 2006. Incorporating green-area user groups in urban ecosystem management. Ambio 35:237-244. http://dx.doi.org/10.1579/05-A-098R.1
Coleman, E. A., and B. C. Steed. 2009. Monitoring and sanctioning in the commons: an application to forestry. Ecological Economics 68:2106-2113. http://dx.doi.org/10.1016/ j.ecolecon.2009.02.006

Community Associations Institute. 2012. Industry data. Community Associations Institute, Falls Church, Virginia, USA. [online] URL: http://www.caionline.org/info/research/ Pages/default.aspx

Connell, J. H. 1978. Diversity in tropical rain forests and coral reefs-high diversity of trees and corals is maintained only in a non-equilibrium state. Science 199:1302-1310. http://dx. doi.org/10.1126/science.199.4335.1302

Cook, E. M., S. J. Hall, and K. L. Larson. 2011. Residential landscapes as social-ecological systems: a synthesis of multiscalar interactions between people and their home environment. Urban Ecosystems 15:19-52. http://dx.doi. org/10.1007/s11252-011-0197-0

Cooper, C. B., J. Dickinson, T. Phillips, and R. Bonney. 2007. Citizen science as a tool for conservation in residential ecosystems. Ecology and Society 12.

Czech, B., P. R. Krausman, and P. K. Devers. 2000. Economic associations among causes of species endangerment in the United States. BioScience 50:593-601. http://dx.doi. org/10.1641/0006-3568(2000)050[0593:EAACOS]2.0.CO;2

Daniels, G. D., and J. B. Kirkpatrick 2006. Does variation in garden characteristics influence the conservation of birds in suburbia? Biological Conservation 133:326-335. http://dx. doi.org/http://dx.doi.org/10.1016/j.biocon.2006.06.011

Ernstson, H., S. Barthel, E. Andersson, and S. T. Borgström. 2010. Scale-crossing brokers and network governance of urban ecosystem services: the case of Stockholm. Ecology and Society 15.

ESRI. 2006. ArcMap 9.2. ESRI, Redlands, California, USA.

Faeth, S. H., C. Bang, and S. Saari. 2011. Urban biodiversity: patterns and mechanisms. Annals of the New York Academy of Sciences 1223:69-81. http://dx.doi.org/10.1111/ j.1749-6632.2010.05925.x

Farr, D. 2008. Sustainable urbanism: design with nature. Wiley and Sons, New York, New York, USA.

Fernandez-Juricic, E. 2000. Avifaunal use of wooded streets in an urban landscape. Conservation Biology 14:513-521. http://dx.doi.org/10.1046/j.1523-1739.2000.98600.x

Fokidis, H. B. 2011. Homeowners associations: friend or foe to native desert avifauna? Conservation concerns and opportunities for research. Journal of Arid Environments 75:394-396. http://dx.doi.org/10.1016/j.jaridenv.2010.12.003 
Franzese, P. A. 2005. Privatization and its discontents: common interest communities and the rise of government for "the nice." Urban Lawyer 37:335-357.

Fuller, R. A., K. N. Irvine, P. Devine-Wright, P. H. Warren, and K. J. Gaston. 2007. Psychological benefits of greenspace increase with biodiversity. Biology Letters 3:390-394. http:// dx.doi.org/10.1098/rsbl.2007.0149

Fuller, R. A., P. H. Warren, P. R. Armsworth, O. Barbosa, and K. J. Gaston. 2008. Garden bird feeding predicts the structure of urban avian assemblages. Diversity and Distributions 14:131-137. http://dx.doi.org/10.1111/j.1472-4642.2007.00439. $\underline{x}$

Goddard, M. A., A. J. Dougill, and T. G. Benton. 2010. Scaling up from gardens: biodiversity conservation in urban environments. Trends in Ecology and Evolution 25:90-98. http://dx.doi.org/10.1016/j.tree.2009.07.016

Grimm, N. B., S. H. Faeth, N. E. Golubiewski, C. L. Redman, J. Wu, X. Bai, and J. M. Briggs. 2008. Global change and the ecology of cities. Science 319:756. http://dx.doi.org/10.1126/ science.1150195

Grimm, N. B., and C. L. Redman. 2004. Approaches to the study of urban ecosystems: the case of central ArizonaPhoenix. Urban Ecosystems 7:199-213. http://dx.doi. org/10.1023/B:UECO.0000044036.59953.a1

Hanula, J. L., D. D. Wade, J. O'Brien, and S. C. Loeb. 2009. Ground-dwelling arthropod association with coarse woody debris following long-term dormant season prescribed burning in the longleaf pine flatwoods of north Florida. Florida Entomologist 92:229-242. http://dx.doi. org/10.1653/024.092.0206

Hersperger, A. M. 2006. Spatial adjacencies and interactions: neighborhood mosaics for landscape ecological planning. Landscape and Urban Planning 77:227-239. http://dx.doi. org/10.1016/j.landurbplan.2005.02.009

Hope, D., C. Gries, W. X. Zhu, W. F. Fagan, C. L. Redman, N. B. Grimm, A. L. Nelson, C. Martin, and A. Kinzig. 2003. Socioeconomics drive urban plant diversity. Proceedings of the National Academy of Sciences of the United States of America 100:8788-8792. http://dx.doi.org/10.1073/pnas.1537557100

Horwitz, P., M. Lindsay, and M. O'Connor. 2001. Biodiversity, endemism, sense of place, and public health: inter-relationships for Australian inland aquatic systems. Ecosystem Health 7(4):253-265. doi: 10.1045/ j.1526-0992.2001.01044.x http://dx.doi.org/10.1045/ j.1526-0992.2001.01044.x

Hostetler, M., and C. S. Holling. 2000. Detecting the scales at which birds respond to structure in urban landscapes. Urban Ecosystems 4:25-54. http://dx.doi.org/10.1023/A:1009587719462
Irvine, K. N., P. Devine-Wright, and S. R. Payne. 2009. Green space, soundscape and urban sustainability: an interdisciplinary, empirical study. Local Environment 14:155-172. http://dx. doi.org/10.1080/13549830802522061

LaCour-Little, M., and S. Malpezzi. 2001. Gated communities and property values. In Proceedings, American Real Estate and Urban Economic Association's Meeting, Washington, D. C., USA.

Larson, K. L., D. Casagrande, S. L. Harlan, and S. T. Yabiku. 2009. Residents' yard choices and rationales in a desert city: social priorities, ecological impacts, and decision tradeoffs. Environmental Management 44:921-937. http://dx.doi. org/10.1007/s00267-009-9353-1

Larson, K. L., S. Hall, E. Cook, B. Funke, C. Strawhacker, and K. Turner. 2008. Social-ecological dynamics of residential landscapes: human drivers of management practices and ecological structure in an urban ecosystem context. Workshop report. [online] URL: http://caplter.asu. edu/docs/papers/2008/CAPLTER/Larson etal 2008.pdf

Lerman, S. B., and P. S. Warren. 2011. The conservation value of residential landscapes: linking birds and people. Ecological Applications 21:1327-1339. http://dx.doi.org/10.1890/10-0423.1

Loss, S. R., M. O. Ruiz, and J. D. Brawn. 2009. Relationships between avian diversity, neighborhood age, income, and environmental characteristics of an urban landscape. Biological Conservation 142:2578-2585. http://dx.doi. org/10.1016/j.biocon.2009.06.004

Luck, G. W., and L. T. Smallbone. 2011. The impact of urbanization on taxonomic and functional similarity among bird communities. Journal of Biogeography 38:894-906. http://dx.doi.org/10.1111/j.1365-2699.2010.02449.x

Martin, C. A., K. A. Peterson, and L. B. Stabler. 2003. Residential landscaping in Phoenix, Arizona, U.S.: practices and preferences relative to covenants, codes, and restrictions. Journal of Arboriculture 29:9-17.

Marzluff, J. M. 2005. Island biogeography for an urbanizing world: how extinction and colonization may determine biological diversity in human-dominated landscapes. Urban Ecosystems 8:157-177. http://dx.doi.org/10.1007/s11252-005-4378-6

McCabe, B. C. 2005. The rules are different here: an institutional comparison of cities and homeowner associations. Administration and Society 37:404-425. http:// dx.doi.org/10.1177/0095399705277137

McCune, B., and J. B. Grace. 2002. Analysis of ecological communities. MjM Software Design, Gleneden Beach, Oregon, USA. 
McKenzie, E. 1996. Privatopia: homeowner associations and the rise of residential private government. Yale University Press, New Haven, Connecticut, USA.

McKenzie, E. 1998. Homeowner associations and California politics; an exploratory analysis. Urban Affairs Review 34:5276. http://dx.doi.org/10.1177/107808749803400103

McKenzie, E. 2003. Common-interest housing in the communities of tomorrow. Housing Policy Debate 14: 203234. http://dx.doi.org/10.1080/10511482.2003.9521473

McKinney, M. L. 2006. Urbanization as a major cause of biotic homogenization. Biological Conservation 127:247-260. http://dx.doi.org/10.1016/j.biocon.2005.09.005

Melles, S. J. 2005. Urban birds diversity as an indicator of human social diversity and economic inequality in Vancouver, British Columbia. Urban Habitats 3:25-48.

Milder, J. C. 2007. A framework for understanding conservation development and its ecological implications. BioScience 57:757-768. http://dx.doi.org/10.1641/B570908

Miller, J. R. 2005. Biodiversity conservation and the extinction of experience. Trends in Ecology and Evolution 20:430-434. http://dx.doi.org/10.1016/j.tree.2005.05.013

Moilanen, A., B. J. Anderson, F. Eigenbrod, A. Heinemeyer, D. B. Roy, S. Gillings, P. R. Armsworth, K. J. Gaston, and C. D. Thomas. 2011. Balancing alternative land uses in conservation prioritization. Ecological Applications 21:14191426. http://dx.doi.org/10.1890/10-1865.1

Moilanen, A., A. Franco, R. Early, R. Fox, B. Wintle, and C. Thomas. 2005. Prioritizing multiple-use landscapes for conservation: methods for large multi-species planning problems. Proceedings of the Royal Society B-Biological Sciences 272:1885-1891. http://dx.doi.org/10.1098/rspb.2005.3164

Nassauer, J. I. 1995. Messy ecosystems, orderly frames. Landscape Journal 14:161-170.

Odum, W. 1982. Environmental degradation and the tyranny of small decisions. BioScience 32:728-729. http://dx.doi. org $/ 10.2307 / 1308718$

Oksanen, J., R. Kindt, P. Legendre, B. O'Hara, G. L. Simpson, P. Solymos, M. H. H. Stevens, and H. Wagner. 2009. Vegan: community ecology package. $\mathrm{R}$ package version 1.15-4. [online] URL: http://CRAN.R-project.org/package=vegan

Ostrom, E. 2009. A general framework for analyzing sustainability of social-ecological systems. Science 325:419422. http://dx.doi.org/10.1126/science.1172133

Ostrom, E., and H. Nagendra. 2006. Insights on linking forests, trees, and people from the air, on the ground, and in the laboratory. Proceedings of the National Academy of Sciences of the United States of America 103:19224-19231. http://dx. doi.org/10.1073/pnas.0607962103
Pagdee, A., Y. S. Kim, and P. J. Daugherty. 2006. What makes community forest management successful: a meta-study from community forests throughout the world. Society and Natural Resources 19:33-52. http://dx.doi.org/10.1080/08941920500323260

Papachristos, D. P., and P. G. Milonas. 2008. Adverse effects of soil applied insecticides on the predatory coccinellid Hippodamia undecimnotata (Coleoptera: Coccinellidae). Biological Control 47:77-81. http://dx.doi.org/10.1016/j. biocontrol.2008.06.009

Pejchar, L., P. M. Morgan, M. R. Caldwell, C. Palmer, and G. C. Daily. 2007. Evaluating the potential for conservation development: biophysical, economic, and institutional perspectives. Conservation Biology 21:69-78. http://dx.doi. org/10.1111/j.1523-1739.2006.00572.x

Pike, M. A. 2009. Green building red lighted by homeowners' associations. William and Mary Environmental Law and Policy Reviews 33: 3.

$\mathrm{R}$ Development Core Team. 2008. R: A language and environment for statistical computing. $\mathrm{R}$ Foundation for Statistical Computing, Vienna, Austria. [online] URL: http:// www.R-project.org

Rosenzweig, M. L. 2003. Win-win ecology: how the Earth's species can survive in the midst of human enterprise. Oxford University Press, New York, New York, USA.

Rudd, H., J. Vala, and V. Schaefer. 2002. Importance of backyard habitat in a comprehensive biodiversity conservation strategy: a connectivity analysis of urban green spaces. Restoration Ecology 10:368-375. http://dx.doi. org/10.1046/j.1526-100X.2002.02041.X

Ryan, R. L. 2005. Exploring the effects of environmental experience on attachment to urban natural areas. Environment and Behavior 37:3-42. http://dx.doi.org/10.1177/0013916504264147

Shochat, E., S. B. Lerman, J. M. Anderies, P. S. Warren, S. H. Faeth, and C. H. Nilon. 2010. Invasion, competition, and biodiversity loss in urban ecosystems. BioScience 60:199208. http://dx.doi.org/10.1525/bio.2010.60.3.6

Slone, D. K., D. R. Goldstein, and W. A. Gowder. 2008. A legal guide to urban and sustainable development for planners, developers, and architects. Wiley, Toronto, Ontario, Canada.

Sousa, J. P., J. V. Vingada, H. Barrocas, and M. M. daGama. 1997. Effects of introduced exotic tree species on Collembola communities: the importance of management techniques. Pedobiologia 41:145-153.

Sustainable Sites Initiative. 2009. Guidelines and performance benchmarks. American Association of Landscape Architects, Washington, D.C.; Lady Bird Johnson Wildflower Center, Austin, Texas; United States Botanic Garden, Washington, D.C., USA. [online] URL: http://www. 
sustainablesites.org/report/Guidelines\%20and\%20Performance\% 20Benchmarks 2009.pdf.

Turner, V. K., and D. C. Ibes. 2011. The impact of homeowners associations on residential water demand management in Phoenix, Arizona. Urban Geography 32:1167-1188. http:// dx.doi.org/10.2747/0272-3638.32.8.1167

Turner, W., T. Nakamura, and M. Dinetti. 2004. Global urbanization and the separation of humans from nature. BioScience 54:585-590. http://dx.doi.org/10.1641/0006-3568 (2004)054[0585:GUATSO]2.0.CO:2

United Nations Population Fund (UNFPA). 2007. UNFPA state of world population 2007: unleashing the potential of urban growth. United Nations Population Fund, New York, New York, USA.

U.S. Census Bureau. 2000. American factfinder. Census of population and housing summary file. U.S. Census Bureau, Washington, D.C., USA. [online] URL: http://factfinder. census.gov

U.S. Green Building Council. 2011. LEED for neighborhood development registered pilot projects and plans list. [online] URL: http://www.usgbc.org/ShowFile.aspx?DocumentID=2960

Walker, J. S., N. B. Grimm, J. M. Briggs, C. Gries, and L. Dugan. 2009. Effects of urbanization on plant species diversity in central Arizona. Frontiers in Ecology and the Environment 7:465-470. http://dx.doi.org/10.1890/080084

Warren, P. S., S. B. Lerman, and N. D. Charney. 2008. Plants of a feather: spatial autocorrelation of gardening practices in suburban neighborhoods. Biological Conservation 141:3-4. http://dx.doi.org/10.1016/j.biocon.2007.10.005

Yang, W., and J. Kang. 2005. Soundscape and sound preferences in urban squares: a case study in Sheffield. Journal of Urban Design 10:61-80. http://dx.doi.org/10.1080/13574$\underline{800500062395}$ 